\title{
Virtual scarce water embodied in inter-provincial electricity
}

\section{transmission in China}

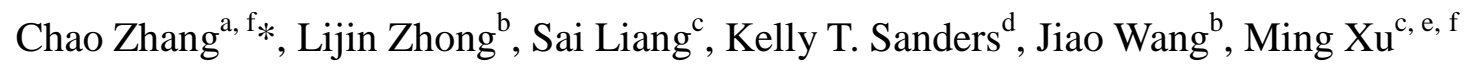

a. School of Economics and Management, Tongji University, 1239 Siping Road, Shanghai 200092, China

b. World Resources Institute China Office, 9 Dongzhong Street, Beijing 100027, China

c. School of Natural Resources and Environment, University of Michigan, Ann Arbor, Michigan 48109-1041, United States

d. Sonny Astani Department of Civil and Environmental Engineering, University of Southern California, 3620 S. Vermont Avenue, Los Angeles, California 90089-2531, United States

e. Department of Civil and Environmental Engineering, University of Michigan, Ann Arbor, Michigan 48109-2125, United States

f. Tongji University Sustainable Development and New-Type Urbanization Think-Tank, Tongji

University, 1239 Siping Road, Shanghai 200092, China

\begin{abstract}
Intra-national electricity transmission drives virtual water transfer from electricity production regions to electricity consumption regions. In China, the water-intensive thermoelectric power industry is expanding quickly in many water-scarce energy production hubs in northern and northwestern provinces. This study constructed a node-flow model of inter-province electricity transmission to investigate the virtual water and scarcity-adjusted virtual water (or virtual scarce water) embodied in the electricity transmission network. It is revealed that total inter-provincial virtual water transfer embodied in electricity transmission was 623 million $\mathrm{m}^{3}$ in 2011, equivalent to $12.7 \%$ of the national total thermoelectric water consumption. The top three largest single virtual water flows are West Inner Mongolia-to-Beijing (44 million $\mathrm{m}^{3}$ ), East Inner Mongolia-to-Liaoning (39 million $\mathrm{m}^{3}$ ), and Guizhou-to-Guangdong $\left(37\right.$ million $\mathrm{m}^{3}$ ). If the actual volumes of consumptive water use are translated into scarcity-adjusted water consumption based on Water Stress Index, West Inner Mongolia $\left(81\right.$ million $\left.\mathrm{m}^{3}\right)$, Shanxi $\left(63\right.$ million $\left.\mathrm{m}^{3}\right)$ and Ningxia $\left(30\right.$ million $\left.\mathrm{m}^{3}\right)$ become the top three exporters of virtual scarce water. Many ongoing long-distance electricity transmission projects in China will enlarge the scale of scarce water outflows from northwestern regions and potentially increase their water stress.
\end{abstract}

\section{Keywords}

electricity transmission; virtual water; scarce water; energy-water nexus; China

\section{Corresponding Author (*)}

E-mail: chao zhang@ @ongji.edu.cn; Phone: +86 21 65982272;

Fax: +862165986304 


\section{Introduction}

Water scarcity is a growing challenge for the power industry globally. ${ }^{[1-4]}$ Although the large-scale dissemination of water-lean renewable electricity technologies (particularly wind turbines and solar photovoltaics) demonstrates the potential to decrease the power sector's reliance on scare water resources ${ }^{[5,6]}$, water-intensive thermoelectric power generation sources will still play a dominant role in the global electricity mix for decades. Water stress has already become a constraint on power reliability and capacity expansion, especially in countries that rely heavily on thermal power, such as the U.S. and China ${ }^{[7,8]}$ Power reliability can be compromised when water is unavailable in sufficient quantities or when water becomes too warm to safely and efficiently cool a facility. ${ }^{[9,10]}$ Unfortunately, these conditions are often coupled at the times of year when demand for power is highest, underscoring the importance of managing these resources in tandem.

The growing tension between water availability and reliable power generation has inspired a growing number of studies to investigate the interactions between power sector development and water resources at different spatial scales. ${ }^{[10-18]}$ A series of recent analyses have evaluated the power-water nexus in China. Zhang et al. ${ }^{[16]}$ evaluated water stress of thermoelectric power generation at river basin level based on a high spatial resolution water use inventory of China's power sector. Cai et al. ${ }^{[19]}$ predicted water withdrawals for energy production in China through 2030 based on the International Energy Agency's energy strategy scenarios and concluded that two-thirds of energy production in China will be located in regions facing water scarcity. Liao et al. ${ }^{[20]}$ estimated water withdrawals and consumption of China's thermoelectric power sector through 2050 under alternative energy development scenarios and concluded that water withdrawals would likely exceed the industrial water quota under the ' 3 Red Lines' policy (i.e. Ministry of Water Resource's policy that imposes water withdrawal and water pollution load caps, while promoting water use efficiency ${ }^{[21]}$ ) in the east, the central and the northern regions.

A growing amount of newly built large coal mines and coal-fired thermal power plants are being developed in China's northwestern regions, which are already under extremely high water stress. ${ }^{[22-24]}$ The fraction of China's thermoelectric capacity located in six water scarce northern and northwestern provinces including Shanxi, Inner Mongolia, Shaanxi, Gansu, Ningxia, and Xinjiang grew from $16 \%$ to $24 \%$ (i.e. 46 gigawatt, GW, to $222 \mathrm{GW}$ ) between 2003 and 2014, respectively. ${ }^{[25]}$ The changing spatial distribution of China's power industry is a consequence of the West-to-East Electricity Transmission Project initialized in the 1990s, which aims to link electricity demand hubs in more developed eastern regions to electricity production hubs in less developed western regions by long-distance high-capacity electricity transmission corridors. ${ }^{\text {[26-28] }}$ While this energy development strategy has achieved multifold social-economics benefits, such as meeting soaring electricity demands in eastern coastal regions, boosting economic development in inland regions, and relieving air pollution in densely populated eastern regions, the water resource impacts of these power sector development trends should also not be neglected. Some recent studies have highlighted these regions. For example, Shang, et al. ${ }^{[29]}$ predicted the water resource demand of fourteen major coal mining and coal-fired power production hubs through 2020 and compared their water demand to available water supply capacities. Yuan et al. ${ }^{[30]}$ concluded that water consumption for coal-fired power generation in six western provinces where major coal production hubs are located will possibly double from 2012 to 2020. 
All the aforementioned studies focus on the water resource demand of energy production. The spatial separation between electricity consumption and production also implies that local water consumption by power generation in western regions is increasingly driven by energy consumers far away in eastern regions. Thus, along with transmitted electricity, there are also transmissions of large volumes of virtual water ${ }^{[31,32]}$ embodied in the electricity. Previous analyses have revealed the intra-national virtual water transfers among Chinese provinces using monetary multi-regional input-output (MRIO) models with extended water use accounts. ${ }^{[33-38]}$ These studies reach a similar conclusion that water scarce regions in northwestern China export virtual water to the country's eastern and southern regions, implying that the spatial patterns of virtual water transfers do not match the spatial distribution of water resources availability in China. The power industry is one of the major contributors to such virtual water transfer patterns in China. Zhu et al. ${ }^{[39]}$ and Guo et al. ${ }^{[40]}$ investigated the virtual water embodied in China's electricity transmission at the sub-national level, which groups the national grid into six units. Their analyses indicate that water resource scarcity should be an important concern in planning large-scale electricity generation and transmission projects. However, electricity transmission often occurs between provinces, so analysis aggregated at the sub-national level loses many important details regarding the spatial patterns of water stress, leading to lost information and inaccuracies in the virtual water network. Since water is a local resource, analysis across a more disaggregated spatial-extent, would have greater utility for informing water resource management.

To better understand the spatial distribution of electricity supply and demand and its impact on local water resources, this study makes three significant improvements over previous studies by: 1) modeling China's grid system at the provincial level, which enables understanding of the internal transmission of water within, as well as across, sub-national grids to identify the spatial distribution of water stress more accurately; 2) adopting a nation-wide water use inventory of China's thermoelectric power industry from Zhang et al. ${ }^{[16]}$ which was the first electric generation unit (EGU) level inventory conducted for China, providing a more detailed and accurate estimate for water consumption for electricity production; and 3) applying the Water Stress Index (WSI) at catchment level from Pfister et al. ${ }^{[41]}$ to further translate volumes of virtual water into scarcity-adjusted virtual water (or virtual scarce water). These improvements in terms of spatial resolution and data quality provide a more accurate assessment of the impact of large scale electricity transmission on local water resources and reveal insights and challenges overlooked in previous studies.

\section{Method}

A node-flow model is constructed to depict China's power system and the virtual water transfers embodied in inter-provincial electricity transmission. ${ }^{[39,40]}$ The power grid in each province is characterized as a node within the national power system. For each node, there are two groups of electricity inflows: 1) electricity produced by local power plants that feed into the provincial grid, and 2) electricity imported from all other provincial grids and/or from other countries (See Figure 1 for an illustration of the node-flow model). On the other hand, there are also two groups of electricity outflows for each node: 1) electricity supplied to local consumers (e.g., factories, household, and public buildings, etc.) by the provincial grid, and 2) electricity exported to all other 
provincial grids and/or to other countries.

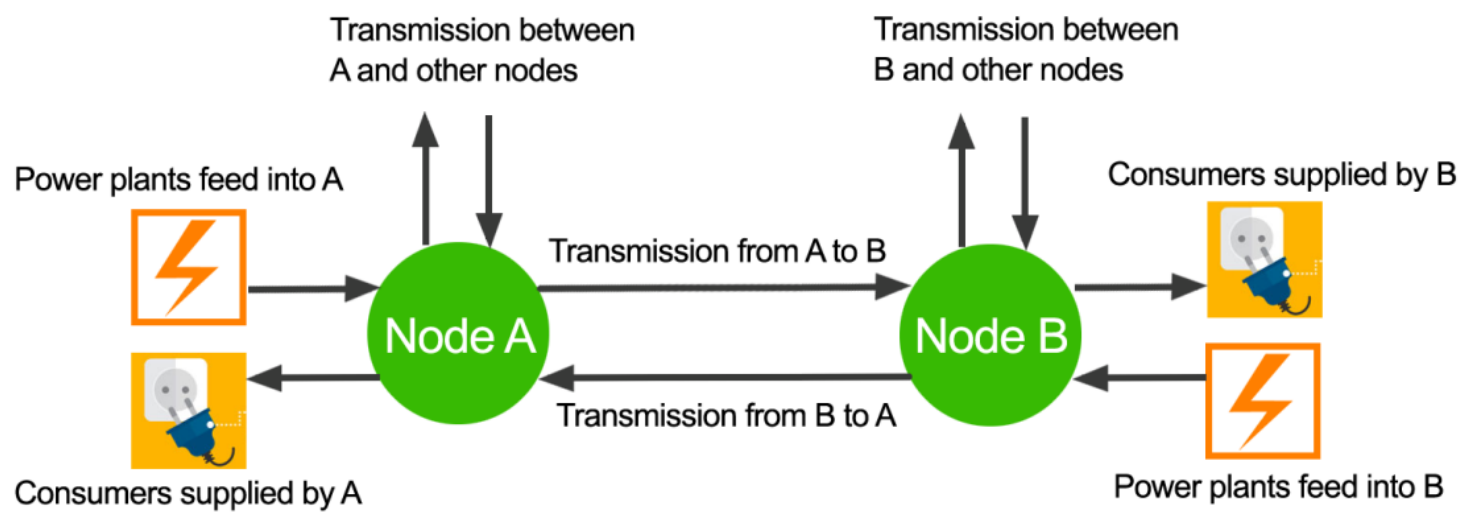

\section{Electricity flow}

\section{Figure 1. An illustration of the node-flow model for grid system.}

Provincial grids (nodes) are inter-linked through electricity transmission lines. Line losses during electricity transmission are assigned to the delivering side (i.e. the region or entities exporting power to the point-of-demand). Therefore, the total amount of electricity flowing into a node (i.e. electricity production by local power plants plus imported electricity from other nodes) equals to the total amount of electricity flowing out of that node (i.e. electricity supplied to local consumers plus electricity exported to other nodes). Assuming there are $K$ nodes belonging to a set $\mathbf{N}$,

$\mathrm{N}=\{1,2,3, \cdots, K\}$, the balance between electricity inflows and outflows for node $i$ can be expressed by Eq. 1 .

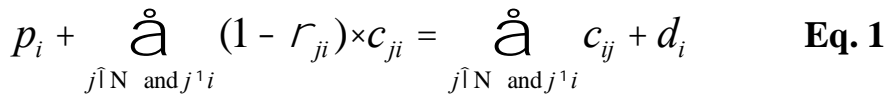

where $p_{i}$ is the total amount of electricity fed into grid $i$ by local power plants, $c_{j i}$ represents electricity transmitted from grid $j$ to grid $i$ measured at the delivering side. Electricity received by grid $i$ is adjusted by the rate of transmission loss ${ }_{j i}$. $d_{i}$ is the amount of electricity supplied to local consumers by grid $i$.

According to the widely used assumption in virtual water analysis, all fluxes of goods and services (in this study, electricity) bear a certain amount of embodied virtual water that can be further traced along the supply chain. Based on this assumption, the total amount of embodied virtual water flows into a node also equals the total amount of embodied virtual water flows out of that node. Electricity coming from different sources is mixed in each node before it is supplied to local consumers or exported to other nodes, such that all fluxes of electricity leaving a node should have the same virtual water content. Therefore, the balance relation between virtual water inflows and outflows for node $i$ can be expressed by Eq. 2 . 
$p_{i} \cdot d f_{i}+\sum_{j \in \mathrm{N} \text { and } j \neq i}\left(1 \quad{ }_{j i}\right) \cdot c_{j i} \cdot e f_{j i}=\left(\sum_{j \in \mathrm{N} \text { and } j \neq i} c_{i j}+d_{i}\right) \cdot e f_{i}$

Eq. 2

116 where $d f_{i}$ is the average direct water consumption factor of electricity fed into grid $i$ by local

117 power plants, $e f_{j i}$ is the embodied virtual water factor of electricity received by grid $i$ from grid $j$,

$118 e f_{i}$ is the embodied virtual water factor of electricity delivered by grid $i$. The relation between $e f_{j i}$

119 and $e f_{i}$ can be expressed by Eq. 3.

120
$(1 \quad j) \times c_{j i} \times e f_{j i}=c_{j i} \times e f_{j}$
Eq. 3

121 Substituting Eq. 3 into Eq. 2, the balance is reorganized in Eq. 4, eliminating the rate of transmission

$122 \operatorname{loss} j i^{*}$

$p_{i} \cdot d f_{i}+\sum_{j \in \mathrm{N} \text { and } j \neq i} c_{j i} \cdot e f_{j}=\left(\sum_{j \in \mathrm{N} \text { and } j \neq i} c_{i j}+d_{i}\right) \cdot e f_{i} \quad$ Eq. 4

The average direct water consumption factors $d f_{i}$ were calculated based on a national-wide plant-level water use inventory of power industry developed by Zhang et al. ${ }^{[16]}$ (described in section 3.3) according to Eq. 5.

127

$$
d f_{i}=\frac{m \mathrm{M}^{i}}{p_{m} c_{m}}
$$

where $m$ represents a power plant, $\mathrm{M}^{i}$ is a set of all power plants feed into node $i, w c_{m}$ is the

129 volume of consumptive water use of power plant $m$, and $p_{m}$ is the amount of electricity feeding

130 into node i by power plant $m$.

The node-by-node balance equations can be re-organized and expressed in matrix form for simplicity. Based on Eq.4, an transmission matrix $\mathbf{T}$ can be constructed as shown in Eq. 6 :

$134 \quad \mathrm{~T}=\left\{\begin{array}{cccc}\sum_{j \neq 1} c_{1 j}+d_{1} & -c_{21} & \cdots & -c_{n 1} \\ -c_{12} & \sum_{j \neq 2} c_{2 j}+d_{2} & \cdots & -c_{n 2} \\ \vdots & \vdots & \ddots & \vdots \\ -c_{1 n} & -c_{2 n} & \cdots & \sum_{j \neq n} c_{n j}+d_{n}\end{array}\right\}$

Eq. 6 
The equation system represented by Eq. 4 is then transformed into Eq. 7:

\section{$\hat{\mathrm{P}} \rtimes \mathrm{DF}=\mathrm{T} \rtimes \mathrm{EF} \quad$ Eq. 7}

where $\mathrm{P}=\left[p_{1}, \cdots, p_{i}, \cdots, p_{n}\right]^{\mathrm{T}}, \mathrm{DF}=\left[d f_{1}, \cdots, d f_{i}, \cdots, d f_{n}\right]^{\mathrm{T}}$, and $\mathrm{EF}=\left[e f_{1}, \cdots, e f_{i}, \cdots, e f_{n}\right]^{\mathrm{T}}$,

$\hat{P}$ represents the diagonalization of vector $\mathrm{P}$. Thus, the embodied virtual water factors of electricity delivered by all nodes (vector $\mathbf{E F}$ ) can be calculated according to Eq. 8 .

\section{$\mathrm{EF}=\mathrm{T}^{1} \times \hat{\mathrm{P}} \times \mathrm{DF} \quad$ Eq. 8}

Both $d f_{i}$ and $e f_{i}$ are measured in $\mathrm{m}^{3} / \mathrm{MWh}$ in term of consumptive water use. We can further

define $\mathrm{T}^{1} \widehat{\mathrm{P}}$ as matrix $\mathbf{L}$. Matrix $\mathbf{L}$ links the direct water consumption factors to the embodied virtual water factors. While the former represents a production-based perspective for water consumption, i.e., direct consumptive water use by electricity generation, the latter represents a consumption-based perspective of water footprint, i.e., virtual water consumption content embodied in electricity received by consumers. The role of matrix $\mathbf{L}$ is similar to the Leontief inverse matrix defined in the traditional input-output analysis, which links final consumption to upstream production. Each element in the matrix $\mathbf{L}$, i.e., $l_{i j}$, represents the amount of electricity generation in province $j$ that is embodied in one unit of electricity consumption or export in province $i$. The virtual water factor per unit electricity consumption or export in province $i$ is represented by Eq.9.

$$
e f_{i}=l_{j \mathrm{~N}} \times d f_{j} \quad \text { Eq. } 9
$$

\section{Data}

\subsection{Divisions of power grid in China}

The power grid in mainland China can be divided at three levels: national, sub-national, and provincial. The national grid is comprised of seven sub-national grids which are further divided into provincial grids serving provincial jurisdictions (see Table 1 and Figure 2). Most of sub-national grids are managed and operated by State Grid Corporation of China (a National-level State-Owned-Enterprise), while the Southern China Grid is operated by China Southern Power Grid Company Limited (a National-level State-Owned-Enterprise) and the West Inner Mongolia Grid is operated by Inner Mongolia Power Company Limited (a local state-owned-enterprise). Figure 2 also presents the electricity mix in each provincial grid. Notably, this study did not include the Tibet Autonomous Region where the grid is isolated with other provinces and the electricity generation capacity is very small. 
Table 1: Power Grid Distribution of China at Sub-National and Provincial Level

\begin{tabular}{|c|c|c|}
\hline Grid Owner \& Operator & Sub-National Grid & Province and/or Prefectures \\
\hline \multirow{27}{*}{$\begin{array}{l}\text { State Grid Corporation } \\
\text { of China (a } \\
\text { National-level SOE) }\end{array}$} & \multirow[t]{5}{*}{ North China Grid } & Beijing (BJ) \\
\hline & & Tianjin (TJ) \\
\hline & & Hebei (HEB) \\
\hline & & Shanxi (SX) \\
\hline & & Shandong (SD) \\
\hline & \multirow[t]{6}{*}{ Northeast China Grid } & East Inner Mongolia (EIM, including \\
\hline & & Chifeng, Tongliao, Xingngn, and \\
\hline & & Hulunbeir) \\
\hline & & Liaoning (LN) \\
\hline & & Jilin (JL) \\
\hline & & Heilongjiang (HLJ) \\
\hline & \multirow[t]{5}{*}{ East China Grid } & Shanghai (SH) \\
\hline & & Jiangsu (JS) \\
\hline & & Zhejiang (ZJ) \\
\hline & & Anhui (AH) \\
\hline & & Fujian (FJ) \\
\hline & \multirow[t]{4}{*}{ Central China Grid } & Jiangxi (JX) \\
\hline & & Henan (HEN) \\
\hline & & Hubei (HUB) \\
\hline & & Hunan (HUN) \\
\hline & \multirow[t]{2}{*}{ Southwest China Grid } & Chongqing (CQ) \\
\hline & & Sichuan (SC) \\
\hline & \multirow[t]{5}{*}{ Northwest China Grid } & Shaanxi (SAX) \\
\hline & & Gansu (GS) \\
\hline & & Qinghai (QH) \\
\hline & & Ningxia (NX) \\
\hline & & Xinjiang (XJ) \\
\hline \multirow{5}{*}{$\begin{array}{l}\text { China Southern Power } \\
\text { Grid Company Limited } \\
\text { (a National-level SOE) }\end{array}$} & \multirow[t]{5}{*}{ China Southern Grid } & Guangdong (GD) \\
\hline & & Guangxi (GX) \\
\hline & & Hainan $(\mathrm{HN})$ \\
\hline & & Guizhou (GZ) \\
\hline & & Yunnan (YN) \\
\hline Inner Mongolia Power & West Inner Mongolia & West Inner Mongolia (WIM, including \\
\hline Company Limited (a & Grid & Alxa, Wuhai, Bayannur, Baotou, Hohhot, \\
\hline Local SOE) & & Ulanchap, and Xilingol) \\
\hline
\end{tabular}

Note: Province abbreviations are included in brackets. The Tibet Autonomous Region is excluded because it is an isolated grid with a very small generation capacity. 


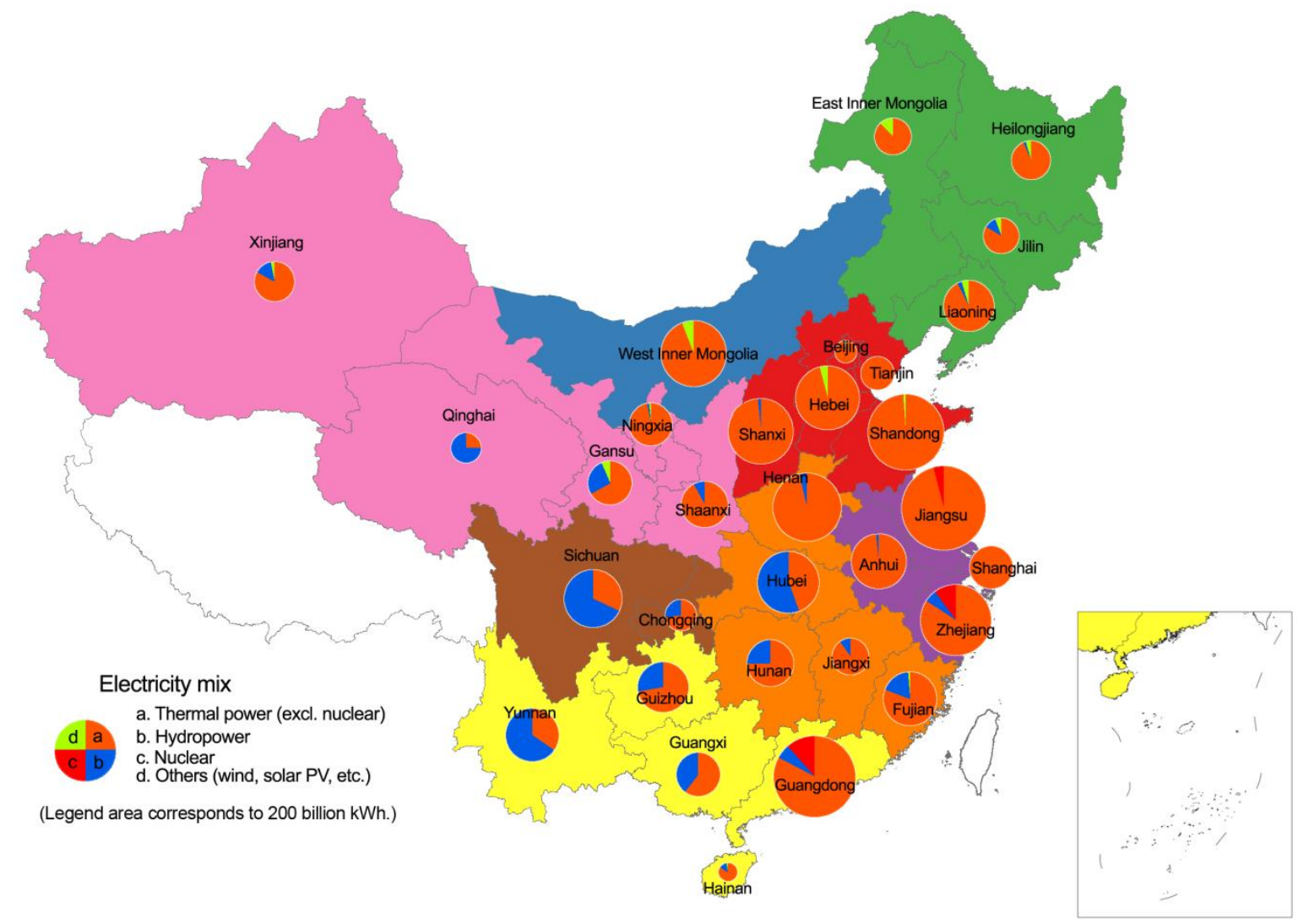

Figure 2. Divisions of China's power grids and their respective electricity mixes in 2011.

\subsection{Inter-provincial electricity transmission}

Electricity transmission data for the provincial grids in 2011 are from the Annual Compilation of Power Industry Statistics by Chinese Electricity Council. ${ }^{[42]}$ The reported amounts of electricity transmission are measured at the delivering side. Most of the electricity transmission data were reported in the form of province-to-province transmission, which can be directly used to construct the transmission matrix $\mathbf{T}$. Some data reported in the form of province-to-sub-national-grid transmission were disaggregated into province-to-province transmissions according to the actual spatial relations of transmission lines between the delivering side and the receiving side. For example, it was reported that 10 billion $\mathrm{kWh}$ electricity was transmitted from Liaoning province to the North China Grid. Further investigation shows that the power grid in Liaoning is connected to the power grid in Hebei. In such case, electricity transmitted from Liaoning to the North China Grid is assigned to Hebei.

Inter-provincial electricity transmission is plotted in a circular diagram by the Circos tool ${ }^{[43]}$ as shown in Figure 3, providing a clear view of the west-to-east geographic pattern of electricity transmission in China. In 2011, the total amount of inter-provincial electricity transmission was 649 billion $\mathrm{kWh}$, accounting for $13.7 \%$ of the national total electricity output (4731 billion $\mathrm{kWh}$ ). $42 \%$ of these transmissions ( 272 billion $\mathrm{kWh}$ ) were across sub-national grids. The largest flux of inter-sub-national transmissions is that from West Inner Mongolia Grid to the North China Grid (85 billion $\mathrm{kWh}$ ). Other large single inter-sub-national transmissions include Ningxia-to-Shandong (26 
billion kWh), Shaanxi-to-Hebei (23 billion kWh), Hubei-to-Shanghai (21 billion kWh), and Shanxi-to-Jiangsu (16 billion kWh).

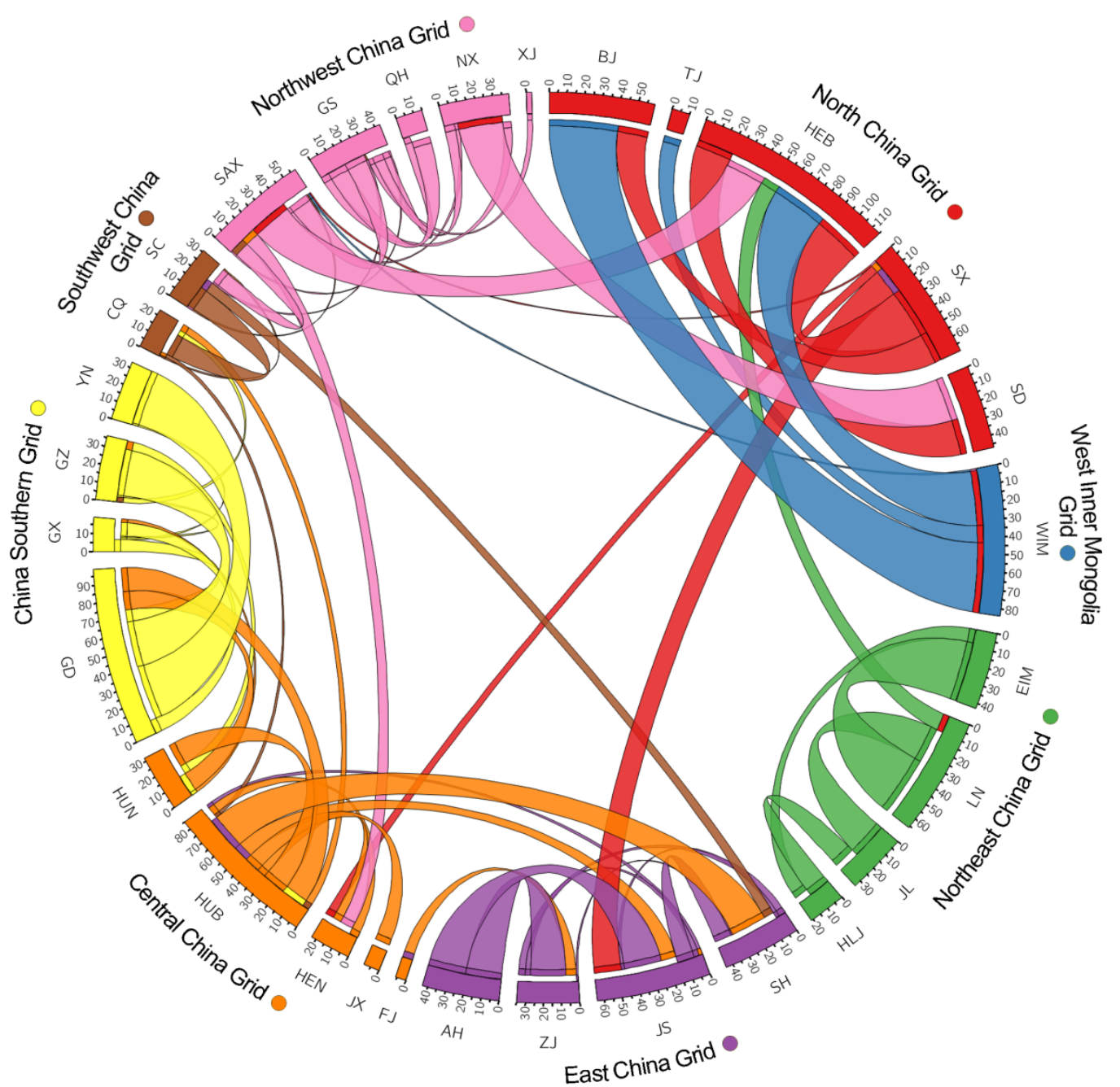

Figure 3. A circular diagram of inter-provincial electricity transmission in 2011. All values are in billion $\mathrm{kWh}$. The width of the flows corresponds to the amount of electricity transmission measured at the delivering side. The color of the flows is defined according to the color of corresponding delivering grids.

\subsection{Water consumption inventory of thermal power industry}

Quantifying water consumption by power generation accurately is essential for calculating the virtual water transfer embodied in the electricity transmission. Based on a detailed water withdrawal/consumption inventory of thermal power plants in China developed in our previous study ${ }^{[16]}$, water withdrawal and consumption for each electric generating unit (EGU)/power plant were estimated according to their fuel type, unit size, cooling technology, and water source by using China specific water withdrawal/consumption factors. Geographic locations of more than 3000 EGUs/plants, covering $98.5 \%$ of the total installed thermal power capacity in China in 2011, were identified to facilitate spatial analysis of water stress associated with power generation.

We do not include water footprint of hydropower in this study. Although hydropower should be taken into consideration in a more comprehensive study, there are still methodological debates on 
how to quantify its water footprint. Alternative methods proposed include evaporative water losses from a reservoir, net water consumption considering land use changes imposed by a dam, and a more complicated net water balance approach considering both water input and output of a reservoir. ${ }^{[44,45]}$ Results vary tremendously depending on the methodology selected, even for the same hydropower plant. A recent study on Chinese hydropower plants, utilizing an evaporative water loss approach, concluded that water footprint per unit electricity generation of China's hydropower plants, influenced primarily by the reservoir area per unit of installed capacity, vary by up to seven orders of magnitude. ${ }^{[46]}$ Due to such large uncertainty, we only investigate consumptive water use by thermoelectric generation in this study, which offers clear accounting boundaries and reliable data.

\subsection{Scarcity-adjusted water consumption}

In order to reflect the spatial differences of water scarcity, we adopted the water stress index (WSI) developed by Pfister et al. ${ }^{[41]}$ with a spatial resolution of $0.5^{\circ}$ to adjust the physical volumes of water consumption by power generators into values reflecting water-scarcity. As shown in Eq. 10, the WSI is calculated by using a logistic function to transform a modified water withdrawal-to-availability $\left(W T A^{*}\right)^{1}$ indicator for a given catchment into a dimensionless continuous value between 0.01 and 1 . Such transformation describes a non-linear S-shaped relationship between water stress and WTA. A WSI of 0.5 corresponds to a WTA of 0.4 , which is usually regarded as a threshold between medium and high water stress ${ }^{[47]}$.

$$
W S I=\frac{1}{1+e^{-6.4 \cdot W T A^{*}}\left(\frac{1}{0.01}-1\right)}
$$

Scarcity-adjusted water consumption was calculated for each EGU/plant by multiplying its volumetric water consumption and corresponding WSI value at its catchment location, and then aggregating values at the provincial level. A scarcity-adjusted direct water consumption factor for each province, $d f_{i}^{\text {scarcity }}$, could then be calculated with Eq. 11, which reflects a scarcity-adjusted embodied water footprint factor, $e f_{i}^{\text {scarcity }}$.

$d f_{i}^{\text {scarcity }}=\frac{\sum_{m \in \mathrm{M}^{i}} w c_{m} \cdot W S I_{m}}{\sum_{m \in \mathrm{M}^{i}} p_{m}}$

\section{Results}

\subsection{Water consumption footprint factors of electricity consumption in actual and} scarcity-adjusted volumes

The water consumption footprint factors per unit electricity consumption vary across provinces (see dark and light blue columns in Figure 3). Generally speaking, electricity consumed in the northern and northwestern regions of China has a higher water footprint than electricity consumed in

\footnotetext{
${ }^{1}$ The modified water withdrawal-to-availability indicator takes the variability of precipitation into consideration and differentiates watersheds with strongly regulated flows.
} 
southern and southwestern regions. These differences are driven primarily by different fuel and cooling technology mixes in different provinces. For large electricity importing provinces, the water intensities of imported electricity also play significant roles in determining the water footprint factors. Electricity consumption in Fujian had the lowest water footprint, $0.42 \mathrm{~m}^{3} / \mathrm{MWh}$.

Thermoelectric generation using re-circulating cooling technology, which has the highest intensity of consumptive water use among all cooling alternatives, only accounted for $7.3 \%$ of the total electricity output in Fujian in 2011. Power plant cooling with seawater and once-through cooling played dominant roles in its generation fleet, which offer lower water consumption at the expense of high water withdrawals. In contrast, electricity consumption in Henan has the highest consumptive water footprint factor of $1.77 \mathrm{~m}^{3} / \mathrm{MWh}$, since thermoelectric generation with re-circulating cooling accounted for $92 \%$ of Henan's total electricity output.

Water footprints associated with local and external water resources are also distinguished in Figure 4. For example, as a major importer of electricity, about $60 \%$ of the water footprint by Beijing's electricity consumption can be attributed to external water resources from West Inner Mongolia and Shanxi (also see Figure 7).

While investigating the scarcity-adjusted water footprint (see dark and light orange columns in Figure 4), differences among provinces are significant due to very uneven spatial distributions of water stress across China. Provinces covered by the Central China Grid, China Southern Grid, and Southwest China Grid except Henan (i.e., Fujian, Jiangxi, Hubei, Hunan, Guangdong, Guangxi, Guizhou, Yunnan, Hainan, Chongqing, and Sichuan) have much lower scarcity-adjusted water footprints per unit electricity consumption (mostly lower than $0.05 \mathrm{~m}^{3} / \mathrm{MWh}$ ) when compared with China's north and northwest regions. In all provinces covered by the North China Grid and the Northwest China Grid, scarcity-adjusted water footprint factors are similar to corresponding factors measured in terms of actual water consumption volumes due to high levels of water stress in those regions. It is interesting to note that although the actual water footprint factors are similar in West and East Inner Mongolia, their scarcity-adjusted values have a large differences reflecting high discrepancies in terms of the water stress in the western and eastern parts of Inner Mongolia. 


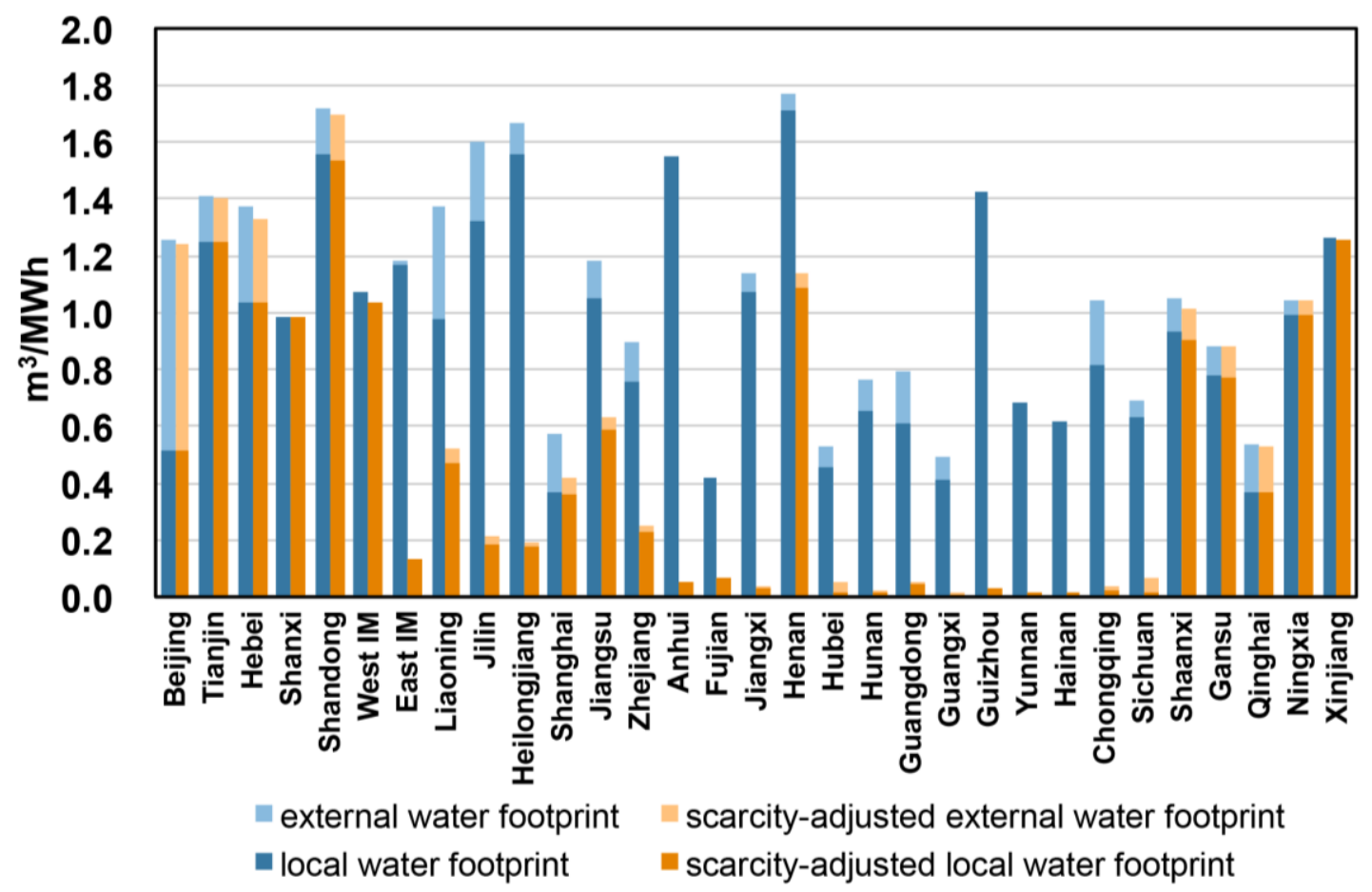

Figure 4. Water consumption footprint factors of electricity consumption by province. Local water footprints refer to the consumptive water use embedded in electricity generated and consumed within the designated province. External water footprints refer to the consumptive water use embedded in electricity consumed in the designated province but generated in other provinces.

\subsection{Structure of actual and scarcity-adjusted virtual water inflows and outflows by province} Major net electricity importing provinces are also net virtual water inflow provinces (See Figure 5). These provinces can be classified into three clusters, which include the most developed and populated areas in China: Beijing-Tianjin-Hebei area in North China (with 62, 11, and 72 million $\mathrm{m}^{3}$ net virtual water inflows, respectively), Shanghai-Jiangsu-Zhejiang area in the east coastal region (with 25,38 , and 40 million $\mathrm{m}^{3}$ net inflows, respectively), and Guangdong in the south coastal region (with 70 million $\mathrm{m}^{3}$ net inflow). Shandong and Liaoning in the northern and northeastern coastal area also have large volumes of net virtual water inflows (55 and 62 million $\mathrm{m}^{3}$, respectively).

On the other hand, major electricity exporting provinces, particularly those with very high proportions of thermoelectric power generation, have significant net virtual water outflows. West and East Inner Mongolia total 130 million $\mathrm{m}^{3}$ of net virtual water outflow. Other provinces with large amounts of net virtual water outflows include Anhui (64 million $\left.\mathrm{m}^{3}\right)$, Shanxi $\left(63 \mathrm{million}^{3}\right.$ ), Guizhou (47 million $\left.\mathrm{m}^{3}\right)$, Ningxia $\left(27\right.$ million $\left.\mathrm{m}^{3}\right)$, and Hubei (25 million $\left.\mathrm{m}^{3}\right)$.

Scarcity-adjusted virtual water inflows and outflows illustrated in Figure 6 show prominent differences in water stress across China. Only northwest regions (particularly West Inner Mongolia, Ningxia, and Gansu) and Shanxi have notable volumes of scarce water outflows. Most power plants in these regions are located in catchments under extremely high water stress, with WSI values of 1. Scarce water outflows from other provinces are negligible. Beijing, Hebei, and Shandong receive most of the scarce water transfers via electricity transmission. 


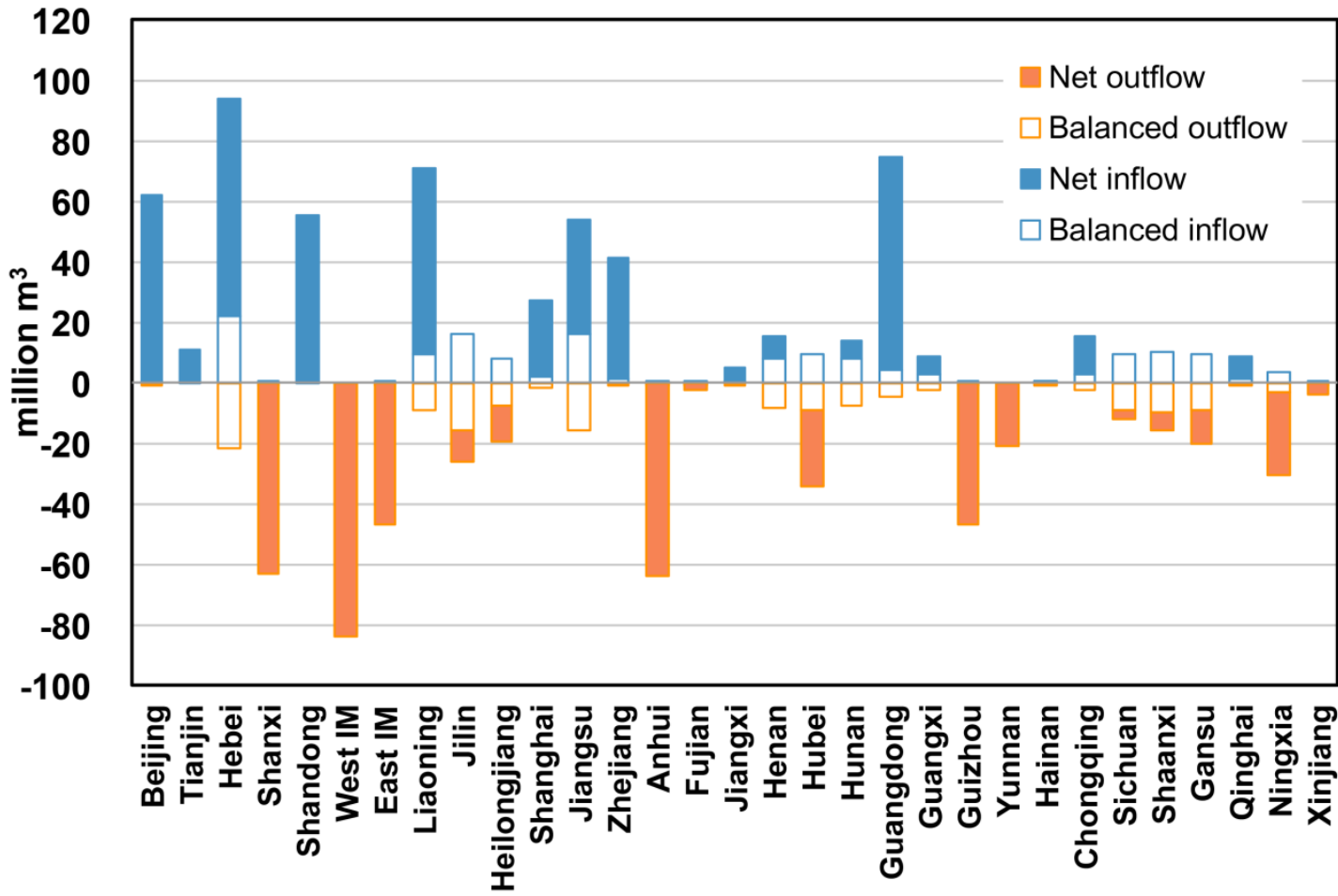

Figure 5. Virtual water inflows and outflows embedded in electricity transmission by province. Virtual water inflows refer to the total external water footprint embodied in the electricity imported into a certain province. Virtual water outflows refer to the total local water footprint embodied in the electricity exported out of a certain province. The net inflow/outflow value reflects the difference between total inflow and outflow.

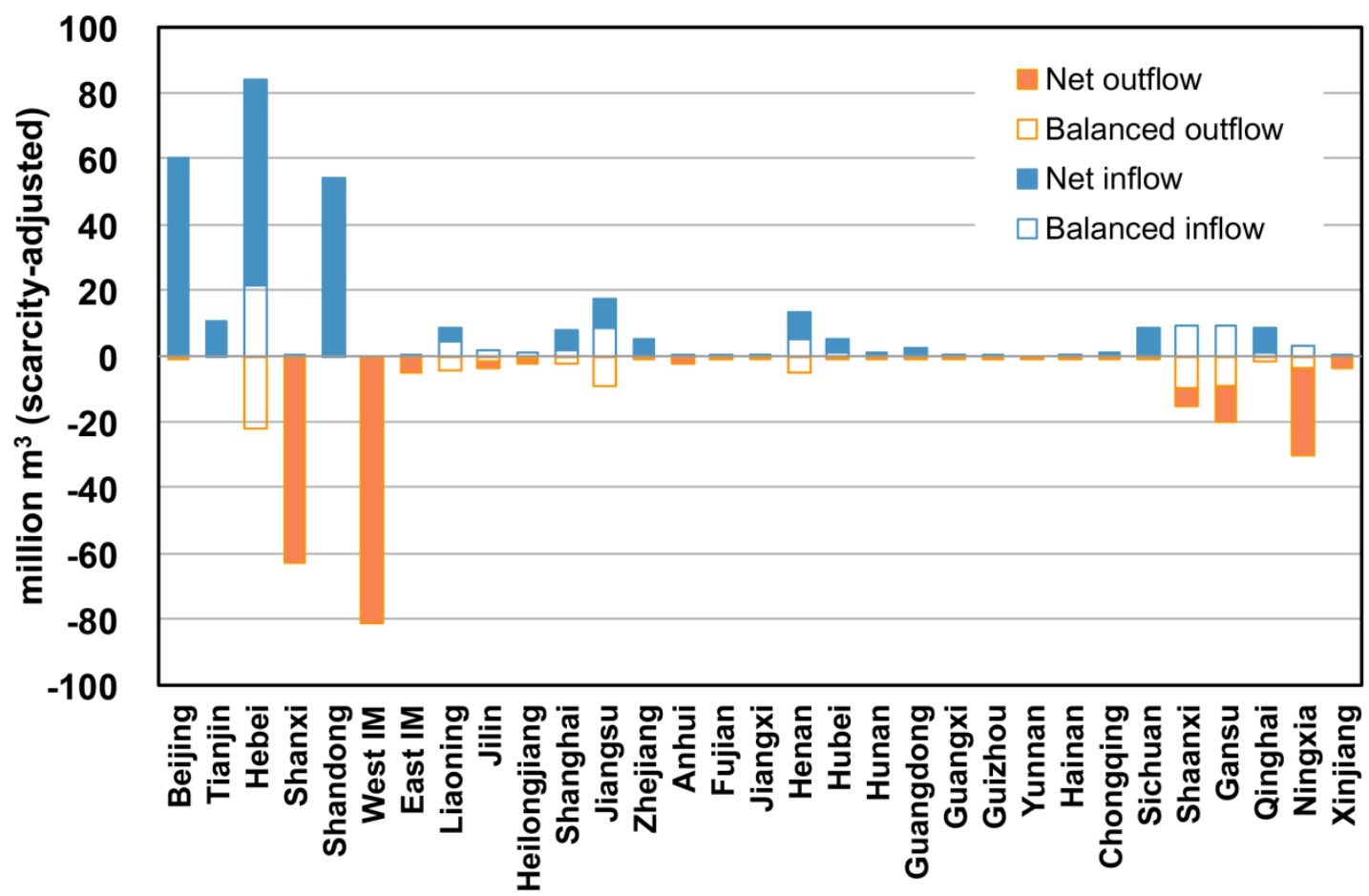

Figure 6. Scarcity-adjusted virtual water inflows and outflows embedded in electricity transmission by province. 


\subsection{Circular diagram of inter-provincial virtual water transfer}

Actual and scarcity-adjusted inter-provincial virtual water transfers are presented in circular diagrams in Figure 7 and 8, respectively. Comparing these two figures with Figure 3 (inter-provincial electricity transmission) reveals a clear view of how differences in water footprint factors shape the virtual water transfer networks embodied in electricity transmission.

The volumes of inter-provincial virtual water transfers add up to 623 million $\mathrm{m}^{3}$, accounting for $12.7 \%$ of the national total thermoelectric water consumption ( 4.89 billion $\mathrm{m}^{3}$ ). This percentage is slightly lower than the fraction of inter-provincial electricity transmission to China's total national electricity output; in other words, the average water intensity of transmitted electricity is slightly lower than the national average water intensity of electricity production. The three largest single virtual water flows are West Inner Mongolia-to-Beijing (44 million $\mathrm{m}^{3}$ ), East Inner Mongolia-to-Liaoning (39 million $\mathrm{m}^{3}$ ), and Guizhou-to-Guangdong (37 million $\mathrm{m}^{3}$ ). Of all the inter- provincial virtual water transfers, 250 million $\mathrm{m}^{3}(40 \%)$ can also be defined as transfers across sub-national grids. The largest inter-sub-national-grid virtual water transfer is that from West Inner Mongolia Grid to North China Grid (89 million $\left.\mathrm{m}^{3}\right)$.

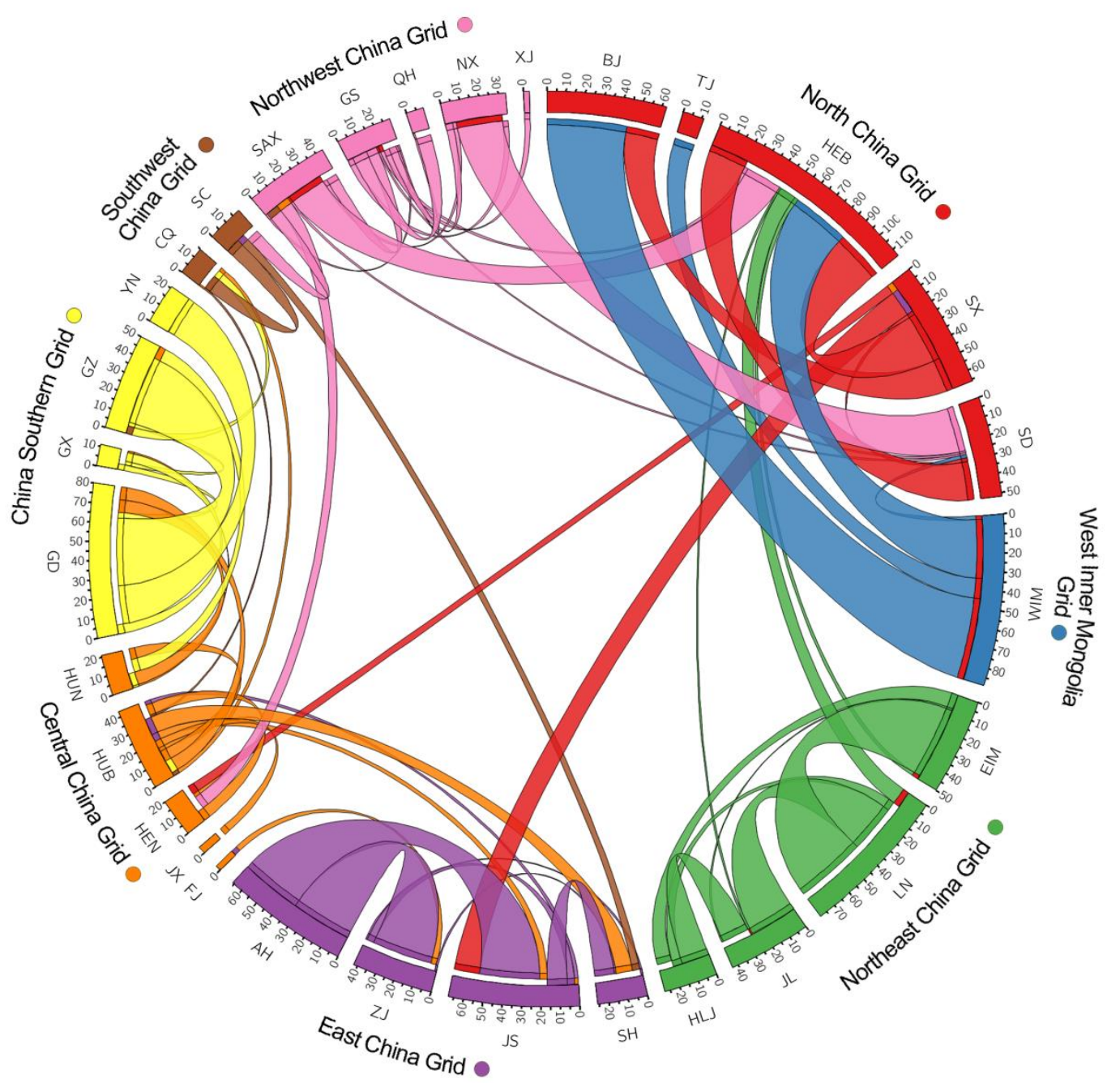

Figure 7. Inter-provincial virtual water transfers embedded in electricity transmission. Flows smaller than 1 million $\mathrm{m}^{3}$ are not displayed in this figure. 
The most notable observation is the significant difference between transferred virtual water patterns measured in terms of the actual volumes versus the scarcity-adjusted volumes. Scarce water transfers added up to 314 million $\mathrm{m}^{3}$, accounting for $11.8 \%$ of the national total scarce water consumption by power industry (2667 million $\mathrm{m}^{3}$ of scarce water). Electricity exported from provinces in the Southwest Grid, Southern Grid, Central Grid, East Grid, and Northeast Grid relies relatively little on scarce water, such that their shares in the circular diagram in Figure 8 are relatively small. Scarce water transfers are dominated by two sub-national grids, i.e., North Grid and Northwest Grid, and West Inner Mongolia Grid.

Over half $\left(59 \% ; 184\right.$ million $\left.\mathrm{m}^{3}\right)$ of inter-provincial transfers of scarce water are also transfers across sub-national grids. The North China Grid received 86 million $\mathrm{m}^{3}$ of scarce water from West Inner Mongolia Grid, compared with the corresponding 89 million $\mathrm{m}^{3}$ of actual water transfer. Other large transfer across sub-national grids include Ningxia-to-Shandong (25 million $\mathrm{m}^{3}$ ), Shaanxi-to-Hebei (19 million $\mathrm{m}^{3}$ ), and Shanxi-to-Jiangsu (15 million $\left.\mathrm{m}^{3}\right)$. More details about the calculation results are presented in the Supporting Information.

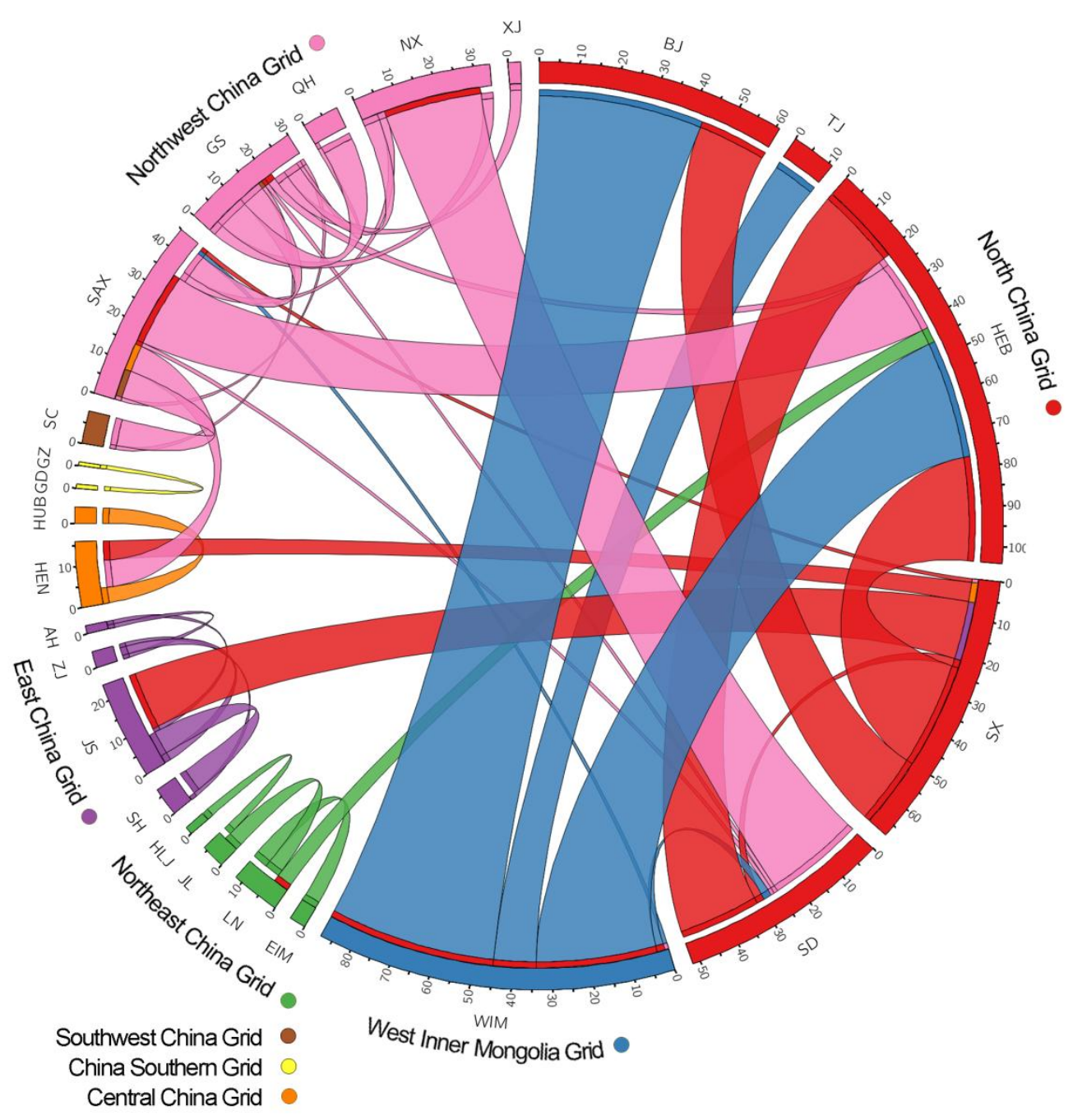
transmission. Flows smaller than 1 million $\mathrm{m}^{3}$ are not displayed in this figure. 


\section{Discussion and conclusions}

This quantitative analysis of the virtual water embodied across China's electricity transmission network at the provincial level reveals many important characteristics of China's electricity-water nexus. The spatial mismatch between socio-economic development and primary energy resources (mainly coal and hydropower) drives the general west-to-east electricity transmission pattern in China. Large urban clusters in the Beijing-Tianjin-Hebei area, the Yangtz River Delta (Shanghai-Jiangsu-Zhejiang area), and the Pearl River Delta (Guangdong) import electricity from inland regions in Northwest China, Central China, and Southwest China to meet their high electricity demands, reflecting the basic spatial structure of inter-provincial electricity transmission. This spatial structure is transformed into a second level inter-provincial virtual water network. Its structure is further detailed in terms of the electricity mix and cooling technology mix in exporting provinces. Electricity exporting provinces with large coal power capacities play a dominant role in shaping this second level virtual water network. China's major coal power producing provinces in the west have large volumes of net virtual water outflows.

The second level virtual water network can be further interpreted into the scarce water network by taking water stress into consideration. The characteristics of the scarce water network are determined by the level of water scarcity in exporting provinces. The significant role of West Inner Mongolia, Shanxi, and the northwestern provinces in scarce water transfers implies that water resource scarcity should be a prominent environmental concern for the developing coal power industry in these exporting provinces. In fact, technological measures have been taken to address the water constraints of coal power industry mainly by adopting air-cooling technology for newly built power plants in North and Northwest China. Analysis by Zhang et al. ${ }^{[23]}$ has shown that large fleets of air-cooled coal power capacity have effectively freed up tremendous volumes of scarce water and reduced the average water intensity of electricity output in Shanxi and West Inner Mongolia. But such water savings are not a free lunch since air-cooling technologies have some drawbacks compared with traditional wet cooling technologies, such as higher investment costs, efficiency penalties at the power plant level, and consequently, higher fuel consumption and carbon and pollution emissions per unit electricity output. ${ }^{[7]}$

It is also revealed that more than half of the inter-provincial scarce water transfers is among sub-national grids. This observation shows that scarce water transfers embodied in electricity transmission are, to a large extent, attributed to long-distance electricity transmission across sub-national grids. The construction of ultra-high voltage (UHV) electricity transmission lines linking China's sub-national grids in recent years has increased nation-wide connectivity and the large-scale dispatching ability of grids, while has at the same time resulted in a spatial shift of environmental pressures associated with power generation. Water resource stress and water-related ecological damages are among the most concerning environmental impacts. ${ }^{[48,49]}$

Scarce water outflows embodied in electricity transmission from the Northwest China Grid are very likely to grow substantially in the near future. The Action Plan for Energy Development Strategy (2014-2020) issued by Chinese State Council in 2014 placed emphasis on "developing long-distance high-capacity electricity transmission technologies, expanding the scale of 
west-to-east electricity transmission, and implementing north-to-south electricity transmission projects" ${ }^{228]}$. Although a growing proportion of electric generation capacity in northwestern provinces will be renewable energy such as wind power and solar PV, the total scale of coal-fired thermoelectric generation is still expanding quickly. For example, Xinjiang had been experiencing rapid increase of coal power capacity, from $95 \mathrm{GW}$ in the beginning of 2010 to $385 \mathrm{GW}$ by the end of 2014. The Xinjiang Grid was first connected into the Northwest China Grid in November 2010. The scale of outward electricity transmission from Xinjiang had increased from 3.24 billion kWh in 2011 to 17.52 billion $\mathrm{kWh}$ in $2014^{[50]}$. As drafted in the latest $13^{\text {th }}$ five-year (2016-2020) development plan of the Xinjiang Grid, proposed by State Grid Corporation of China, more than 200 billion RMB (about 30 billion USD) of investment will be made into power grid construction during the $13^{\text {th }}$-five-year period, and the amounts of exporting electricity via 8 west-to-east transmission corridors are expected to reach 300 billion $\mathrm{kWh}$ by the end of $2020 .{ }^{[51]}$ While enjoying the enormous economic benefits and enhanced energy security brought by the leap-frog construction of new power plants and grids ${ }^{[52]}$, the power industry's impacts on water resources in northwest China should also be seriously addressed across its entire life cycle stages including planning, design, construction, and operation.

This analysis uses a highly vetted and generator-specific water consumption inventory of China's power plants with generator-specific WSI values which are not previously available in prior studies. ${ }^{[39,40,53]}$ In order to show the differences between high and low resolution analyses, we merged the data at the sub-national grid level and conducted additional calculations (detailed results can be found in the Supporting Information). Some important data are missing in low resolution analyses. For example, within the North China Grid, Beijing and Hebei are net virtual water importers, and Shanxi and West Inner Mongolia are net exporters. Such details cannot be revealed in sub-national level analysis. Aggregated calculations show that the external scarce water footprint only accounts for 3.5\% of the total scarce water footprint in the North China Grid (49.9 in 1426 million $\mathrm{m}^{3}$ ). If we apply this conclusion to the megacity Beijing, it would be entirely misleading, since about $60 \%$ of the water footprint of electricity consumption in Beijing is traced to Shanxi and West Inner Mongolia. Understanding these details is also informative for assessing regional water balances, developing water resources management policies especially for water scarce regions, and providing actionable insights for future power generation development decisions.

Furthermore, low resolution analysis may result in biased water footprint factors. While evaluating the water resources implications of purchased electricity, the accuracy and reliability of water footprint factors is of key importance. The scarcity-adjusted water footprint per unit electricity consumption in the East China Grid is $0.383 \mathrm{~m}^{3} / \mathrm{MWh}$ (see results of sub-national level calculation in the Supporting Information). However, province level analysis show that these factors in Shanghai, Jiangsu, Zhejiang, Anhui and Fujian (provinces within the East China Grid) are 0.422 $\mathrm{m}^{3} / \mathrm{MWh}, 0.633 \mathrm{~m}^{3} / \mathrm{MWh}, 0.249 \mathrm{~m}^{3} / \mathrm{MWh}, 0.05 \mathrm{~m}^{3} / \mathrm{MWh}$ and $0.064 \mathrm{~m}^{3} / \mathrm{MWh}$, respectively. The differences between sub-national average and local specific factors could be up to one order of magnitude.

Considering the rapid expansion of China's power industry and its shifting spatial pattern, a backward investigation of the historical trajectory of this network and a forward-looking scenario 
analysis in terms of its future trends could be very informative for integrated energy and water resources planning and management. Future studies can be devoted to expanding this issue through establishing long time series datasets with sufficient spatial details.

\section{Acknowledgement}

This study is supported by National Science Foundation of China (71503182), "Chenguang Program" of Shanghai Education Development Foundation (14CG20), and World Resources Institute's "Slowing Coal Growth in Western China by Leveraging Water Stress" Project funded by Hewlett Foundation.

\section{Reference}

[1] Feeley-III TJ, Skone TJ, Stiegel Jr GJ, McNemar A, Nemeth M, Schimmoller B, et al. Water: A critical resource in the thermoelectric power industry. Energy 2008; 33: 1-11.

[2] Koch H, Vogele S, Kaltofen M, Grossmann M, Grunewald U. Security of Water Supply and Electricity Production: Aspects of Integrated Management. Water Resour Manag 2014; 28: 1767-80.

[3] Van Vliet MTH, Vogele S, Rubbelke D. Water constraints on European power supply under climate change: impacts on electricity prices. Environ Res Lett 2013; 8: 035010.

[4] Webster M, Donohoo P, Palmintier B. Water- $\mathrm{CO}_{2}$ trade-offs in electricity generation planning. Nat Clim Chang 2013; 3: 1029-32.

[5] Byers EA, Hall JW, Amezaga JM. Electricity generation and cooling water use: UK pathways to 2050. Global Environ Chang 2014; 25: 16-30.

[6] Johst M, Rothstein B. Reduction of cooling water consumption due to photovoltaic and wind electricity feed-in. Renew Sust Energ Rev 2014; 35: 311-17.

[7] Sanders KT. Critical review: Uncharted waters? The future of the electricity-water nexus. Environ Sci Technol 2015; 49: 51-66.

[8] Zhang C, Anadon LD. Life Cycle Water Use of Energy Production and Its Environmental Impacts in China. Environ Sci Technol 2013, 47, 14459-67.

[9] Bartos MD, Chester MV. Impacts of climate change on electric power supply in the Western United States. Nat Clim Chang 2015; 5: 748-52.

[10] Scanlon BR, Duncan I, Reedy RC. Drought and the water-energy nexus in Texas. Environ Res Lett 2013; 8: 045033.

[11] Gleick PH. Water and Energy. Ann Rev Energ Env 1994; 19: 267-299.

[12] Zhou Y, Li H, Wang K, Bi J. China's energy-water nexus: Spillover effects of energy and water policy. Global Environ Chang 2016; 40: 92-100.

[13] Yates D, Meldrum J, Averyt K. The influence of future electricity mix alternatives on southwestern US water resources. Environ Res Lett 2013; 8: 045005.

[14] DeNooyer TA, Peschel JM, Zhang Z, Stillwell AS. Integrating water resources and power generation: The energy-water nexus in Illinois. Appl Energy 2016; 162: 363-71.

[15] Wang S, Chen B. Energy-water nexus of urban agglomeration based on multiregional input-output tables and ecological network analysis: A case study of the Beijing-Tianjin-Hebei region. Appl Energy 2016; 178: 773-83.

[16] Zhang C, Zhong L, Fu X, Wang J, Wu Z. Revealing Water Stress by the Thermal Power Industry in China Based on a High Spatial Resolution Water Withdrawal and Consumption Inventory. Environ Sci Technol 2016; 50: 1642-52. 
[17] Pfister S, Saner D, Koehler A. The environmental relevance of freshwater consumption in global power production. Int J Life Cycle Assess 2011; 16: 580-91.

[18] Dodder RS. A review of water use in the U.S. electric power sector: insights from systems-level perspectives. Curr Opin Chem Eng 2014; 5: 7-14.

[19] Cai B, Zhang B, Bi J, Zhang W. Energy's Thirst for Water in China. Environ Sci Technol 2014; 48 : 11760-68.

[20] Liao X, Hall JW, Eyre N. Water use in China's thermoelectric power sector. Global Environ Chang 2016; 41: 142-52.

[21] Opinions of the State Council on Applying the Strictest Water Resources Control System. China State Council; 2012.www.gov.cn/zwgk/2012-02/16/content_2067664.htm [in Chinese].

[22] Li J, Qiao J, Wang L-Q, Environmental situations facing westward shift of coal mining and policy recommendations. Envrion Impact Asses 2015; 37: 33-36.

[23] Zhang C, Anadon LD, Mo H, Zhao Z, Liu Z. Water Carbon Trade-off in China's Coal Power Industry. Environ Sci Technol 2014; 48: 11082-89.

[24] Luo T, Otto B, Maddocks A. Majority of China's proposed coal-fired power plants located in water stressed

regions. www.wri.org/blog/2013/08/majority-china\%E2\%80\%99s-proposed-coal-fired-power-plants-located-wa ter-stressed-regions.

[25] China electric power yearbook 2014. China Electric Power Press, Beijing; 2015 [in Chinese].

[26] Zhang C, Zhong L, Fu X, Zhao Z. Managing Scarce Water Resources in China's Coal Power Industry. Environ Manag 2016; 57: 1188-203.

[27] The Twelfth five year (2011-2015) plan of energy development. China State Council; 2013 [in Chinese].

[28] Action Plan for Energy Development Strategy (2014-2020). China State Council; 2014 [in Chinese].

[29] Shang Y, Lu S, Li X, Hei P, Lei X, Gong J, et al. Balancing development of major coal bases with available water resources in China through 2020. Appl Energy; In press( http://dx.doi.org/10.1016/j.apenergy.2016.07.002).

[30] Yuan J, Lei Q, Xiong M, Guo J, Zhao C. Scenario-Based Analysis on Water Resources Implication of Coal Power in Western China. Sustain 2014; 6: 7155-80.

[31] Allan JA. Virtual water: a strategic resource, global solutions to regional deficits. Groundwater 1998; 36: 545-6.

[32] Hoekstra AY, Chapagain AK, Aldaya MM, Mekonnen MM. The Water Footprint Assessment Manual: Setting the Global Standard. Earthscan, London: 2011.

[33] Zhang C, Anadon LD. A multi-regional input-output analysis of domestic virtual water trade and provincial water footprint in China. Ecol Econ 2014; 100: 159-72.

[34] Feng K, Hubacek K, Pfister S, Yu Y, Sun L. Virtual scarce water in China. Environ Sci Technol 2014; 48: 7704-13.

[35] Dong H, Geng Y, Fujita T, Fujii M, Haod D, Yu X. Uncovering regional disparity of China's water footprint and inter-provincial virtual water flows. Sci Total Environ 2015; 500-501: 120-30.

[36] Guo S, Shen GQ. Multiregional Input-Output Model for China's Farm Land and Water Use. Environ Sci Technol 2015; 49: 403-14.

[37] Jiang Y, Cai W, Du P, Pan W, Wang C. Virtual water in interprovincial trade with implications for China's water policy. J Clean Prod 2015; 87: 655-65. 
[38] Zhao X, Liu J, Liu Q, Tillotson MR, Guan D, Hubacek K. Physical and virtual water transfers for regional water stress alleviation in China. PNAS 2015; 112: 1031-5.

[39] Zhu X, Guo R, Chen B, Zhang J, Hayat T, Alsaedi A. Embodiment of virtual water of power generation in the electric power system in China. Appl Energy 2015; 151: 345-54.

[40] Guo R, Zhu X, Chen B, Yue Y. Ecological network analysis of the virtual water network within China's electric power system during 2007-2012. Appl Energy 2016; 168: 110-21.

[41] Pfister S, Koehler A, Hellweg S. Assessing the Environmental Impacts of Freshwater Consumption in LCA. Environ Sci Technol 2009; 43: 4098-104.

[42] Annual compilation of statistics of power industry. China Electricity Council, Beijing; 2012.

[43] Krzywinski M, Schein J, Birol I, Connors J, Gascoyne R, Horsman D, et al. Circos: an information aesthetic for comparative genomics. Genome Res 2009; 19: 1639-45.

[44] Herath I, Deurer M, Horne D, Singh R, Clothier B. The water footprint of hydroelectricity: a methodological comparison from a case study in New Zealand. J Clean Prod 2011; 19: 1582-9.

[45] Mekonnen MM, Hoekstra AY. The blue water footprint of electricity from hydropower. Hydrol Earth Syst Sci 2012; 16: 179-87.

[46] Liu J, Zhao D, Gerbens-Leenes PW, Guan D. China's rising hydropower demand challenges water sector. Sci Rep 2015: 5: 11446.

[47] Gassert F, Luck M, Landis M, Reig P, Shiao T. Aqueduct Global Maps 2.1: Constructing decision-relevant global water risk indicators. World Resources Institute, Washington DC; 2015.

[48] Song X, Pu H, Ma Y. Thirsty coal: study on the water resources problem of mage coal power bases. China Environmental Press, Beijing; 2012 [in Chinese].

[49] Majority of China's proposed coal-fired power plants located in water-stressed regions. World $\begin{array}{llll}\text { Resources } \quad \text { Institute, } & \text { Washington }\end{array}$ http://www.wri.org/blog/2013/08/majority-china\%E2\%80\%99s-proposed-coal-fired-power-plants-locat ed-water-stressed-regions.

[50] Annual Report of Xinjiang Energy Industry 2014. Xinjiang Uygur Autonomous Region Development and Reform Commission; 2015 [in Chinese].

[51] Chen Q. Power Grid Construction Investment will exceed 200 billion RMB in Xinjiang during $13^{\text {th }}$-five-year period. http://www.gov.cn/xinwen/2015-04/14/content_2846136.htm [in Chinese].

[52] Wu Y, Yu Z, Ngan HW, Tan Z. Sustaining China's electricity market development. Energ Policy 2014; 73: 30-7.

[53] Jia L, Liang S, Qu S, Zhang Y, Xu M, Jia X, et al. Greenhouse gas emission factors of purchased electricity from interconnected grids. Appl Energy In press. 


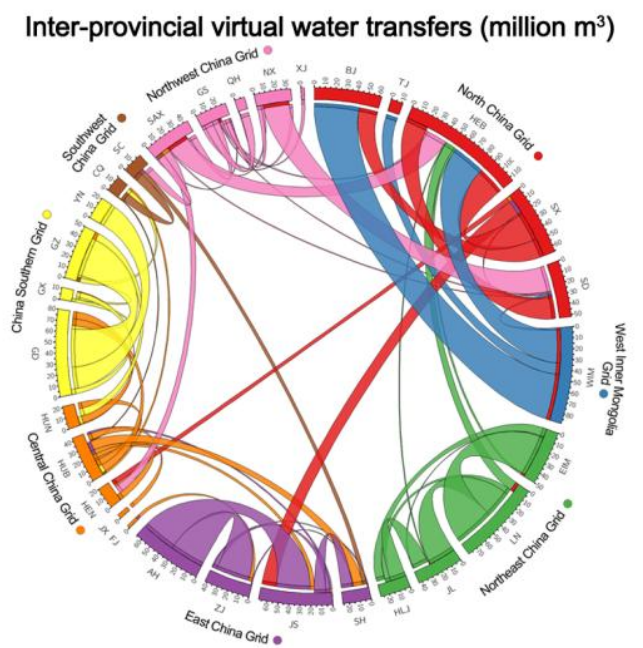

Inter-provincial virtual scarce water transfers (million $\mathrm{m}^{3}$ )

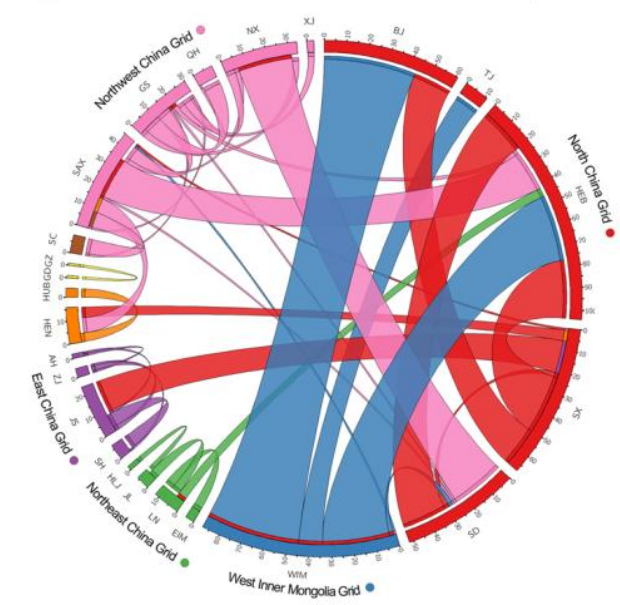

